\title{
Reply to Letter from Dr. Morton, et al.
}

\author{
Amir Mehran
}

Received: 26 November 2008 / Accepted: 3 December 2008 /Published online: 20 December 2008

(C) Springer Science + Business Media, LLC 2008

Hello. We appreciate the comments made by our friends Dr. Morton et al. in response to our aforementioned article. Similar to the notion that "asking three surgeons will get you seven opinions," our routine core bariatric anesthesiologists (including a former Stanford faculty member) feel quite differently about this topic. They believe that a small dose of rocuronium (roc) can be used very safely in these patients without the risk of losing an airway. Roc avoids all of the known side effects of succinylcholine (sux), plus the other concerns specifically related to bariatric patients that were discussed in the article. Their personal experience with sux has been negative with several cases of severe myalgias, hyperkalemia-related cardiac arrest, etc.

In our patient, the clinical presentation was definitely related to the use of sux by a nonbariatric anesthesiologist group member; hence, the recommendation for using a routine core group. Since the typical recommendation of a large randomized trial is not practical, it comes down to institutional preferences based on past experiences and track record of safety.

A. Mehran $(\square)$

Section for Minimally Invasive and Bariatric Surgery,

Department of Surgery, UCLA,

10833 Le Conte Avenue, CHS 72-236,

Los Angeles, CA 90095-6904, USA

e-mail: amehran@mednet.ucla.edu

URL: www.bariatrics.ucla.edu 